\title{
Obesity and immune system impairment: A global problem during the COVID-19 pandemic
}

\author{
Rosa Manca $^{\mathrm{a}, *}$, Francisco Bombillar ${ }^{\mathrm{b}}$, Chester Glomski ${ }^{\mathrm{c}}$ and Alessandra Pica ${ }^{\mathrm{a}}$ \\ ${ }^{a}$ Department of Biology, University of Naples Federico II, Naples, Italy \\ ${ }^{\mathrm{b}}$ Department of Administrative Law, University of Granada, Granada, Spain \\ ${ }^{\mathrm{c}}$ Department of Pathology and Anatomical Sciences, Jacobs School of Medicine, State University of \\ New York, Buffalo, NY, USA
}

Received 16 September 2021

Accepted 29 December 2021

\begin{abstract}
.
BACKGROUND: The production of healthy and nutritious food, in an ecologically sustainable and safe way, has become one of the great ethical issues of our time. The recent G 20 urged the "promotion and work on the social determinants of health to address other critical health issues such as food and nutrition".

OBJECTIVE: The aim of this work is to analyze the current scientific literature regarding the role of obesity in the severe COVID-19 outcomes. In the light of the indications of the G20, the main causes of obesity are examined, and lifestyles are suggested with particular regard to proper nutrition in order to prevent/treat overweight since childhood.

METHODS: Multidisciplinary work, in which the biological and legal perspectives provide a meta-legal analysis of the obesity problem.

RESULTS: Unhealthy habits induce metabolic imbalance and increase in the body weight promoting obesity. This condition is the result of many factors (genetic predisposition, social position and "junk food" consumption) and is associated with a high risk of diseases, among them exacerbations from viral respiratory infections, including the current COVID-19 pandemic.

CONCLUSIONS : The industrial food revolution changed our eating habits, leading to production of too much unhealthy food, absent in ancient diet, thus contributing to the onset of some disorders. The business of food industry should be downsized in favor of morally or ethically fair choices for consumers and for the well-being of society, together with an ethical food distribution, governmental food education programs, and balanced oversight of food production.
\end{abstract}

Keywords: Obesity, ethics of food production, health nutrition, COVID-19, public health legislation

\section{Introduction}

The recent G20 recommended the "promotion and work on the social determinants of health to address other critical health issues such as non-communicable diseases, mental health and food and nutrition". In

\footnotetext{
*Address for correspondence: Rosa Manca, Department of Biology, University of Naples Federico II, Naples, Italy. E-mail: rosa.manca@unina.it.
} 
line with these directives, it is necessary to pay attention on always more emerging obesity in the world, which causes compromission of health status and tendency to morbidity.

One of the great ethical issues of our time is how we provide plentiful, healthy and nutritious food for all, in an environmentally sustainable and safe manner, while addressing the multiple problems of overweight and obesity and micronutrient deficiencies.

Obesity is a pathological condition associated with a high body mass index (BMI, calculated as weight in kilograms divided by height in meters squared) and with a high waist circumference $(\geq 102 \mathrm{~cm}$ for men and $\geq 88 \mathrm{~cm}$ for women) [1]. However, abdominal fat, independent of BMI, was found to be the cause of the systemic inflammation that contributes to chronic disease and to increase the risk of various cancer [2]. Poor diet, low levels of physical activity, and high levels of sedentary activities are risk factors for obesity $[1,3]$. Moreover, studies suggest that obesity is associated with poorer immune response and outcomes in patients with respiratory diseases [4].

Although overweight results from consuming more calories than expended through physical activity, the reality is much more complicated. Unhealthy habits and hypercaloric nutrition result in metabolic imbalance and increase in the body weight promoting obesity [4]. Some of the latter is a result of the onset of "food swamps", which are areas with a high-density of establishments selling high-calorie fast food and junk food [5]. The term "junk food" describes food and drinks low in nutrients and high in calories, saturated fat, added sugar and/or added salt.

Some individuals have a genetic predisposition to obesity. However, research regarding the interaction between gene expressions and life style have revealed that the environment can amplify genetic risk for obesity and related morbidities. However, this risk can be mitigated by increasing physical activity and by health nutrition [6]. Human metabolism is influenced by genetic factors, but food is able to modulate their expression, thereby influencing the status of health and/or diseases [7].

In the present study, the analysis of the current scientific literature regarding the role of obesity in the severe COVID-19 outcomes was conducted. In the light of the indications of the Rome Declaration [8], the main causes of obesity are examined and lifestyles are suggested with particular regard to proper nutrition in order to prevent/treat overweight since childhood.

\section{Childhood obesity begins in prenatal life}

The incidence of childhood obesity has dramatically increased in recent decades and the percentage of obese children in the United States has more than tripled since the 1970s and currently is increasing in other countries such as China [10].

The primary cause of childhood obesity lies in maternal nutrition during pregnancy. In fact, inadequate pre-natal maternal nutrition leads to more vulnerable children $[8,10]$. For mothers-to-be who consult a doctor about pregnancy, body weight is examined as an indicator for the future health of their child-tobe [11]. Obesity in pregnancy is associated with an increased risk of early pregnancy loss, prematurity, fetal anomalies, fetal macrosomia and low birth weight, gestational diabetes, hypertension, cesarean delivery, and postpartum weight retention [12].

Obesity and overweight in childhood are associated to the onset of severe pathologies in the short term and in the long term. In the short term, obese children are predisposed to psychological disorders, such as depression $[12,13]$ and to physical disorders, such as asthma, systemic inflammation and various metabolic diseases [14]. In the long term, overweight in childhood is associated to the onset of the same severe pathologies in adulthood, such as cardiovascular diseases, diabetes, some cancers, and musculoskeletal disorders [15]. 
Since the reduce body weight is very difficult to accomplish once obesity is established, the prevention of obesity in children is not to be underestimated [10]. Moreover, early prevention of overweight and obesity results in the best choice to preserve health in adulthood and in old age [15].

\section{Geographical prevalence of overweight and obesity}

Overweight and obesity are associated with more deaths worldwide, rather than with underweight. In fact, globally there are more people, who are obese, than underweight: this occurs in every region, except parts of sub-Saharan Africa and Asia [16]. The population's diets are influenced by food availability, traditions, and socio-economic status [17], but common dietary patterns have seen a rapid shift from vegetable-based diets to diets with a higher proportion of energy from animal-source foods, added sugars and fats [16,18]. In 2018, an estimated 40 million children, aged 1-5 years, were overweight or obese. Once considered a high-income-country problem, overweight and obesity are now increasing in the lowand middle-income countries, particularly in urban settings. The worldwide prevalence of obesity has doubled since 1980 and a third of the world's population is now classified as overweight or obese. Already, in 2008 Kelly et al. expected that $57.8 \%$ of the world population will be overweight or obese by the year 2030 if the current trends continue [19]. In 2017, the Institute for Health Metrics and Evaluation estimated that America and Europe were the two regions with the highest prevalence of overweight and obesity. In the Americas the prevalence of obesity increased from $12.9 \%$ in 1980 to $28.3 \%$ in 2015. In European region the prevalence of obesity increased from $14.5 \%$ in 1980 to $22.9 \%$ in 2015 [20]. The increase in the prevalence of obesity was observed also in developing countries, such as Nigeria, India and Bangladesh, mainly due to rapid changes in socioeconomic status and demographics, the adoption of an energy- and fat-rich diet and a sedentary lifestyle [21]. In some areas of Africa, the number of overweight children increased by nearly 50 per cent since 2000 [10]. In Europe, the highest proportions of overweight and obese children were observed in southern Italy (boys, 40.7\%; girls 43.1\%), followed by Cyprus and Spain, demonstrating that the several risk factors (i.e. physical activity and unhealthy diet) for childhood obesity are most prevalent in Mediterranean populations [22].

Currently the world population is paradoxically divided between populations that waste food and populations that suffer from hunger. In fact, some countries, such as the UK, the USA and Europe, produce nearly twice as much food as is required for the nutritional needs of their populations [23]. The enormous global food wastage results in a number of ethically questionable implications.

\section{The bad eating habits of our time (fast food and junk food vs slow food)}

Currently characteristics of food, such as quickness of intake, practicality, flavor, cheapness, occasion for relationship with others, condition food choices. However, this often causes the intake of incorrect food behaviors: poor hygiene, distortion of food rhythms, intake of high-calories, incorrect eating behaviors. The fear of not having time is often the basis for not have a breakfast. This trend is more widespread among young women and among obese subjects [24]. Due to the fast-working rhythms, eating snacks or quick meals at fast food restaurants are preferred. The most chosen menu consists of junk food (stuffed and tasty bread and high-calorie meals with a low intake of folic acid, vitamins, and minerals). Excessive intake of this type of foods leads to "fast food disease", that is introduction of high calorie foods with low satiating effects, saturated fatty acids, cholesterol and salt with repercussions on raising the average plasma cholesterol levels at a young age and increase in obesity cases [25]. On the other hand, slower 
eating increases satiety thus decreasing the food intake [26]. Young people are tempted to buy junk food, because it is very cheap and accessible to all [27]. In fact, low socioeconomic status is one of the strongest risk factors for developing obesity [28].

Children are the main consumers of fast food. They are strongly influenced by TV food advertising, which is a significant factor in our "obesogenic" environment [29]. Moreover, maternal "junk food" diet during pregnancy and pre-pregnant overweight can influence high infant birthweight [30].

\section{The role of food in our health}

The food choices are not "innocent" but have great implications, of which we are not always aware. Our consumption and our food choices have repercussions on the environment and irreparably on the future generations [25].

"Let the food be the medicine and medicine be the food" wrote Hippocrates in the 5th century B.C. Diet plays a significant role in shaping human health and disease. The term nutraceutical (nutrition and pharmaceutical), coined in 1989 by Stephen De Felice, indicated that it referred to a food or extract of food providing health benefits, including the prevention and/or treatment of a disease [31].

Many studies agree on the fundamental role of nutrition on the pathogenesis of various diseases. The increasingly frequent development of degenerative diseases is associated with the daily intake of industrial food. Hence, food has a dual role: it can prevent/cure or promote various pathologies.

The intake of nuts and seeds, seafood omega-3 fats, vegetables, fruit, polyunsaturated fats are strongly recommended to maintain health $[3,17]$. With the increasing awareness of the nutraceutical properties of various foods, many authors have come to the conclusion that proper nutrition includes foods that can prevent or cure diseases. Most of nutraceuticals have antioxidant activity with the ability to counteract several pathologies [32]. On the other hand, nutrition determines the subject's blood quality because all the products absorbed in the intestine are delivered to the blood. The normalcy or lack thereof of an individual's blood is one of the principal factors that determines the onset of pathologies.

\section{The role of food in the endocrine system}

Malnutrition represents the main cause of ipo- or infertility [33]. Both overweight and obesity exert an influence upon multiple human body functions including reproductive environment. Worldwide, fertility problems due to male or female factors affect $10 \%$ to $15 \%$ of all couples [33]. Lifestyle, including food intake, has consistently been associated with fertility problems. Fast food and dairy protein intake is associated with a longer time to pregnancy and infertility. In fact, fast foods are rich in saturated and polyunsaturated fats and are correlated with reduced numbers of mature oocytes in women [34]. The adipose tissue acts as endocrine organ and releases a number of bioactive molecules (adipokines) that interact with multiple molecular pathways by inducing insulin resistance, inflammation, hypertension, cardiovascular risk, oocyte maturation and male infertility [5,35]. Other reproductive function, such as endometrial implantation and miscarriage rate can be affected in obese women. On the other hand, weight loss and modification of lifestyle in obese women have demonstrated efficacy in restoring menstrual cyclicity and ovulation and improving the likelihood of conception [5]. Moreover, the weight loss allows improvement of endocrine parameters (decrease of free testosterone, and luteinizing hormone and insulin levels) and the normalization of ovulation frequency [36]. 
Correct eating habits (consumption of whole grains, omega-3 fatty acids, olive oil, fish along with a reduced consumption of trans fats and red meat) may improve overall health and boost fecundity [37]. In addition, multivitamin and folic acid daily intake before and during pregnancy may prevent birth defects and improve the chance of achieving and maintaining a pregnancy [38]. Nevertheless, the presence of high pesticide residues in fruits and vegetables might modify the beneficial effects of these ideal foods on reproductive success [39].

During infections the predisposition of patients is important, in addition to their state of health and nutrition. Adipose tissue plays a role in health status as an endocrine source of adipokines. The altered secretion of adipokines seems to participate in the pathogenesis of obesity-related diseases, including endothelial dysfunction, inflammation, atherosclerosis and several lung diseases such as chronic obstructive pulmonary disease [40]. Adiponectin and $\omega-3$ polyunsaturated fatty acids reduce the production of pro-inflammation interleukin 6 and of other factors, thus preventing the lung inflammation that occurs following some infections. Due to this reduction, the modulation of adiponectin levels can be considered an important way to reduce cytokines levels and the adverse effects related to the current COVID-19 infection [41]. Moreover, the dysregulated secretion of adipocytokines, as well as the increased secretion of proinflammatory cytokines leads to an infiltration of inflammatory immune cells in adipose tissue [42]. These obesity-induced metabolic inflammatory processes, termed "metaflammation", is associated with dysfunctions of immune cells [43] and with onset of several diseases [44].

\section{The false myths of healthy nutrition}

Various researchers have analyzed the relationships of unhealthy diets (high sodium, low nuts/seeds, high processed meats, low seafood omega-3 fats, low vegetables, low fruits, and high sugar-sweetened beverages) with heart disease, stroke, and type 2 diabetes, by considering age, sex, ethnicity, and education of the patients. Nearly half of all the deaths in the United States in 2012 appeared to be caused by cardiometabolic diseases associated with bad eating habits such as the above diets [45].

Many authors attributes to cow's milk the promotion of a great number of pathologies and the absence of protection from osteoporosis and bone fractures [46-48]. Currently, milk/dairy products have been widely recommended to menopausal women and to children. However, it seems that the excessive consumption of dairy products favors the onset of osteoporotic fracture. Aslam et al. [49] demonstrated that women who consumed $\geq 800 \mathrm{~g} / \mathrm{d}$ of dairy products showed higher risk for osteoporotic fracture compared with women consuming moderate levels. Unfortunately, cow's milk is now widely consumed daily by many people worldwide, well beyond the infancy, although there is often an unrecognized intolerance, which leads to the manifestation of various autoimmune disorders due to lactose or casein intolerance, as well as of type 1 diabetes [50]. Moreover, milk intake may influence and anticipate the timing of menarche in girls [49]. Additionally, milk consumption may promote the onset of cancer, especially hormonal cancer (prostate, endometrial, ovarian and breast cancers) due to high level of contained hormones (such as insulin-like growth factor-1 and estrogens) which are able to permit the rapid growth of veal calves and heifers destined to be dairy cows [51]. Nevertheless, the evaluation of breast cancer risk related to nutrition may be difficult to establish due to the interactions among milk/dairy products and other nutrients, which in turn can promote or inhibit carcinogenesis [52].

If on one hand industrial food improved the hygienic safety of its products, it is still recognized, on the other hand, that its methodology utilizes many additives such as maltodextrin, glucose syrup, salt, emulsifiers, organic solvents, gluten, microbial transglutaminase and nanoparticles to improve food 
texture, consistency and color. In this regard it is well known that the aforementioned additives increase intestinal permeability, leading to multiple autoimmune diseases [53]. Gluten intake also correlates with autoimmune diseases as demonstrated in vitro and in vivo studies. Gluten, a complex of proteins, is a major food additive in the "modern" wheat, used by food industry, for its visco-elastic and proteinaceous properties, capable of retaining gas bubbles [54]. A great deal of evidences has demonstrated that gluten displays multiple side effects such as increased intestinal permeability, and microbiome alterations that trigger autoimmune diseases (e.g., celiac disease [a condition characterized by anti-tissue transglutaminase and endomysial antibodies] and inflammatory bowel disease). One of the main gluten inflammatory agents is gliadin, which induces damage to the intestinal wall by originating the leaky gut syndrome and consequent impairment of immune system, up to the onset of autoimmune diseases [55]. Moreover, some conditions apparently unrelated to gluten intake such as non-celiac gluten sensitivity (NCGS), display negative celiac serology while illustrating damage as obtained from gluten sensitivity [56]. According to Rotondi Aufiero et al. [57], no markers for NCGS are available to date. However, the results of research of Losurdo et al. [58] have demonstrated that the gluten intake in NCGS patients leads to an increase of mast cells and decrease of $\mathrm{T}$ helper lymphocytes in the duodenal lamina propria. This status is interpreted as an immune impairment that facilitates the establishment of any diseases, in agreement with Mozzi et al. [59] and Di Fazio [47].

Vegetarianism, a diet devoid of meat and fish selected for moral and health reasons, in its most exaggerated form, veganism, is totally devoid of animal proteins such as milk and derivatives, and eggs. It can cause significant damage to the one's health (e.g., anemia, dehydration, memory loss, premature aging). These conditions are induced because of deficiencies in protein, iron, zinc, calcium, vitamin B12, vitamin D and other nutrients [25].

\section{Nutrients: Amazing modulators of the immune system}

Wrong eating habits influence the immune competence, suppressing immune functions that are fundamental to host protection [60]. In fact, the nutritional deficiency or inadequacy can damage immune functions. The aim of Nutritional Immunology Research is to define the optimal intake of some dietary factors that can enhance the immune system [61].

Food plays an important role in the development and preservation of the immune system; therefore, any nutritional imbalance affects its competence and integrity. The immune system is related to the blood group of a person and a relationship between blood group and eaten food has been hypothesized [62]. This relationship is due to proteins found in foods, called lectins, which have agglutinating properties. Bacteria and other microbes have also lectins on their surfaces, which attach to the slippery mucosal linings of the body. In the same way, food lectins that are incompatible with blood type antigens can create a violent inflammation of sensitive mucus of the intestines and this agglutinative action may mimic food allergies. Moreover, food lectins can interact with the surface receptors of white blood cells, inducing them to multiply rapidly [62]. As recently observed, many foods agglutinate the cells of certain blood types but not others, meaning that a food which may be harmful to the cells of one blood type, may be beneficial to the cells of another [62]. For these reasons, foods not tolerated by a blood type cause an immune reaction, which can lead to inflammation and resulting pathologies. Since a healthy immune system implies a healthy nutrition, it is essential to pay attention on the signs that prelude an immune reaction (cough, nasal secretion, watery eyes) and associate them to food intake [62]. Although, in the past two decades, the consumption of sodium, sugar and fat have been highly criticized [63], it seems 
that dietary risk factors for mortality are diets high in sodium, low in whole grains, low in fruit, low in nuts and seeds, low in vegetables, and low in omega-3 fatty acids [63]. Poor dietary habits associated with a range of chronic diseases can be major contributors to non-communicable disease mortality in all countries worldwide [63].

Some nutrients are required for the efficient function of immune system, including essential amino acids, vitamin A, vitamin E, the essential fatty linoleic acid, folic acid, vitamin B6, vitamin B12, vitamin $\mathrm{C}, \mathrm{Zn}, \mathrm{Cu}, \mathrm{Fe}$ and Se. Deficiencies of one or more of these nutrients may affect all forms of immunity [60].

Vitamin D has been shown to impact on functions of immune cells in both the early innate (fast, nonantigen specific) and the subsequent adaptive (slower, antigen specific) responses. In particular, it enhances the innate antimicrobial immune responses. For these reasons an adequate intake of vitamin D helps to maintain and reinforce the body's defense against infection by promoting the innate immunity [61].

Several studies have demonstrated the protective effects of vitamin E on viral infection. In fact, the vitamin $\mathrm{E}$ has been demonstrated to be able to reduce flu symptoms in mice, a protective effect associated with an improved $\mathrm{T}$ lymphocyte response [62].

In addition, vitamin $\mathrm{C}$ regulates several aspects of immunity, such as supporting epithelial barrier function, growth and function of both innate and adaptive immune cells, white blood cell migration to sites of infection, phagocytosis and microbial killing, and antibody production [64]. Moreover, vitamin $\mathrm{C}$ has a main role in regulating duration and severity of upper respiratory tract infections, both in common cold and in more severe infections [63]. It is noteworthy that the role of vitamin $\mathrm{C}$ in modulating stress effects, based on the relationship between the hypothalamic region (which involved in expression of emotions) and immune system (via physical and psychological stresses), can downregulate immunity [65].

Additionally, the metal zinc is an essential micronutrient involved in several pathways. Zinc deficiency, as well as zinc excess, leads to disorders in immune cell numbers and activities, resulting in increased susceptibility to infections and development of inflammatory diseases. Moreover, zinc homeostasis is crucial for defense against pathogens and for regulating of an over-reactive immune system which causes autoimmune diseases, chronic inflammation or allergies [66].

\section{Gut microbiota and the immune system}

Various micronutrients have been retained as immune system modulators, such as many dietary lipids, in particular marine animal-derived n-3 polyunsaturated fatty acids (PUFA) [67], and probiotic microorganisms including Lactobacillus (L.), Bifidobacterium (B.), and Streptococcus (S.). The latter constitute the gut microbiota which host the largest part of body's immune cells [68].

All the above nutrients may beneficially affect immune function by modulating it and decreasing infection risk [60]. It should be borne in mind that influenza, a single-stranded RNA virus, displaying high mutation rates and rapid evolution, is able to escape from pre-existing neutralizing antibodies in the host [69]. This is presumably also true in the case of the current viral infection from COVID-19.

Therefore, many hygiene practices and well-balanced nutrition help to control the impact of infections by maintaining the optimal function of the immune system.

The need for supplementation with multivitamins and minerals, including vitamins A, B6, B12, C, D, $\mathrm{E}$, and folate is controversial. It may be appropriate for standard consumers, who buy food distributed in the markets, while consumers who have access to fresh products and well-balanced diet may omit this supplementation [70].

The intestinal microbial community plays a main role in metabolic homeostasis and in the proper functioning of the immune system [71]. It participates in nutrient absorption and maintains the health of 
the intestinal tract by producing bioactive compounds and some essential nutrients and metabolites [72]. Although some pathogenic bacteria are also present in intestine tract, they do not negatively alter metabolism so far as the microbiota is healthy. The quality of the microbiota is conditioned by eating habits and microbiota alterations can contribute to induction of obesity and a variety of metabolic diseases. Thus the preservation of a healthy flora is essential to avoid diseases [8]. Gut microbiota can influence the food absorption, lipid metabolism, endocrine functions and thus the immune response. Its components differ greatly in lean versus obese subjects. A lesser diversity and richness of bacteria have been detected in obese subjects [73].

\section{Obesity and COVID-19 infection}

The biology of obesity comprises impaired immunity, chronic inflammation, and blood clotting tendency, all of which conditions can aggravates the "cytokine storm", typical of COVID-19 infection. The risk factors for infection outcomes are even more increased due to the deleterious sedentary lifestyle during pandemic-lockdown. In fact, the social distancing, isolation and related stress have a negative impact on the control of snacking behavior, leading to increments of obesity and metabolic complication [74].

As previously mentioned, obesity leads to the onset of metabolic disease, which in turn causes a weakening of the immune system. The high consumption of saturated fats, sugars, and refined carbohydrates activates the innate immune system and impairs adaptive immunity, leading to chronic inflammation and impaired host defense against viruses [75]. All these conditions are cause the complications of current COVID-19 infection, which can lead to exitus.

Previous studies have shown that excessive weight can increase the risk of developing communityacquired pneumonia and may impede lung function $[76,77]$. Furthermore patients with obesity often need to prolonged mechanical ventilation, in case of acute lung injury [77], because pulmonary function is already compromised by decreased diaphragmatic excursion [78]. Both older people as well as young obese individuals have less cardiorespiratory reserve to cope with COVID-19 infection, leading to a poor prognosis [79].

A high prevalence of malnutrition was demonstrated in COVID-19 patients at hospital admission confirming the role of obesity in the severe COVID-19 outcomes. In addition, obesity condition is commonly associated to micronutrient deficiencies and to alterations of the gut microbiota (dysbiosis), conditions directly influencing immune function and infection risk $[74,80]$. In disadvantaged populations, characterized by low quality diets and lack of access to healthy foods, there is a high prevalence of chronic diseases, such as obesity, and a COVID-19 consequent morbidity. For these reasons, particular attention should be paid to nutritional screening in obese patients [74].

\section{Food health and nutrition: A challenge for the Law}

Since time immemorial one only has to return to the Old Testament (Leviticus 13: 45-46 or Numbers 5: 1-3), to be reminded that political/governmental states have acted in the field of public health with the aim of fighting deadly epidemics and safeguarding the collective health [80]. The response to COVID-19 offers a current day example [81]. But public health having lost its predominant position to individual health care and maintenance in recent times is no longer only concerned with developing programs marked by the application of ablative measures such as quarantines, confinements, lazarets or forced vaccinations. Now 
is the time for an expanded promotion of health. The need is to build health through measures focused on promoting healthy lifestyle habits among the population such as daily and moderate physical activity and an acquisition of beneficial eating habits.

\section{A renewed generation in public health legislation}

The Public Powers articulate a series of measures to fight against non-communicable diseases related to food and the obesity epidemic [81]. Obesity not only jeopardizes the health of vulnerable groups such as minors, but the health, economic and social costs associated with it also put the health of public coffers at risk, by fattening public healthcare and pharmaceutical spending. Hence, the Public Powers act on the determinants of health (diet or lifestyle), as factors unrelated to people's own physiological constitution but which have a decisive impact on their health. The postal code is more important than the genetic code. Diseases are not only fought in hospital beds. The health of the community is also defended by promoting the Mediterranean diet, exponent of our intangible cultural heritage, when configuring the Administration, the nutritional quality of the school dinners of our children (special attention was paid in this aspect in Andalusia by means of the non nata Act for the Promotion of Healthy Living and a Balanced Diet). Food health and nutrition pose a challenge for the Law. This public-administrative intervention transits through a space that in many aspects is part of the sphere of private freedom. It is therefore necessary to define precisely where the limits of this public intervention should be. It is necessary to specify through which legal techniques or powers it is possible to legitimately intervene to eradicate problems as childhood obesity. Beyond the educational and informative measures this sphere of action offers the potential of subjecting those products that present a nutritional danger to a special tax (e.g., such as sugary drinks). Or approaches could be designed that are novel and interesting as the nudges (altering people's behavior in a predictable way without forbidding any options or significantly changing their economic incentives). An example could be putting fruit at eye level in the supermarket without banning junk food [82]. We would like to highlight in this report the use of Audiovisual and Advertising Law (which implies a limitation of commercial speech) as a qualified way to promote healthy lifestyle habits in current homo videns, a new human being who only understands what he sees and for whom only what he sees exists [83]. This legislative "acquis" (the accumulated legislation, legal acts, and court decisions which constitute the total body of EU law) completed with interesting self-regulation codes, affects the promotion of products such as tobacco or alcoholic beverages of less than and more than $20^{\circ}$ (alcohol proof) [84]. Furthermore, a recent pronouncement of the Spanish audiovisual authority is a good example of the sign of the new times, indicating, in reference to the program Man v. Food, that audiovisual communication service providers must exercise a constructive and proactive role to improve communication on healthy habits and diets.

\section{Which strategies to adopt?}

The first step should be the development of educational broadcasts and media, and school nutrition courses about the healthy diet and the role of physical activity in maintaining a healthy state, encouraging all members of society (not just obese individuals) to lead a healthy lifestyle [85]. Correct models proposed or supported by popular, respected, influential individuals benefit the spread of a healthy lifestyle.

A policy to foster the intake of healthy foods could be taxation of sweetened beverages. This would protect the middle- and low- income populations [10]. The improvement of the availability of healthy foods requires a collaborative, constructive acceptance of useful, purposeful, geographically widely based 
regulations by the food industry coupled with a reduction of marketing unhealthy foods. Some wholesome foods that would otherwise be wasted could be maintained for use by modifying the rules for food donation. These could limit the liabilities that accompany the donation of food when farmers, producers and restaurants give food to those in need. A standardization of expiration dates of perishable food as well as a thoughtful analysis how best establish them would be helpful. These rules should be readily available (e.g., perhaps at point of retail purchase) for consumers' understanding of the duration of the usefulness of the food.

The food industry has often maintained that adequate levels of physical activity can compensate or make equivalent a high-energy diet. Conversely, this position has met skepticism, given the scale of the obesity epidemic [14]. The promoting healthy diets necessities the following interventions by the food industry:

- reducing the fat, sugar and salt content of processed foods;

- avoid adding unnecessary and harmful sugars (i.e. maltodextrins);

- inform the consumer with precise and complete labels of the contents of the processed food;

- prohibit the installation of vending machines for unhealthy snack food in schools and public places;

- reducing the consumption of sweet beverage especially by children and young individuals;

- supporting regular, routine physical activity programs at school and at the workplace [10].

Urban planners should rethink their role in society in order to improve urban mobility [14]. Urban design can facilitate or constrain physical activity; the lack of access to parks and open spaces reduces opportunities for physical activity and limit walking. Similarly, the improvement of public transport and the inclusion of cycle paths and pedestrian areas can favor physical activity leading to health benefits and a decrease of pollution [1].

Proposals for the individual

- limit energy intake from fats and sugars;

- increase consumption of fruit and vegetables, as well as legumes, whole grains and nuts;

- engage in regular physical activity (60 minutes a day for children and 150 minutes spread throughout the week for adults) [10].

As the new jobs are awarded to young, smart, hard- working individuals, they are often exposed to sedentary (health-adverse conditions) whose consequences are difficult to reverse in adulthood [14].

\section{Discussion}

The worrying increase in obesity has risen to a worldwide serious public health problem. Since obesity is related to metabolic disease, most clinical researches are devoted to the understanding of the pathogenesis of such diseases. The first cause of diet-related metabolic disease appears to be the incorrect nutrition. The recently acquired knowledges about nutraceuticals has evidenced the principal role of food in the prevention and management of metabolic diseases. The nutraceutical properties of food can be used for suppressing inflammation, improving insulin sensitivity, and/or decreasing fat deposition. On the other hand, it is difficult to conduct significant research on human nutrition. This is due to the variability of eating habits which are influenced by the local culture of different geographic areas and countries and the age of the subjects. Currently, the concept of prevention rather than treatment of metabolic disorders related to diet, is becoming the prevalent thought [7]. The idea of Feuerbach (1862) 
"you are what you eat" has some truth in it; our food choices depend on our tradition and culture and on increasingly world globalization. Eating is also an ethical act: through the act of eating, we are more than just consumers $[25,86]$.

The worldwide prevalence of obesity is increased, even in developing countries, mainly due to rapid changes in socioeconomic and demographic status, the adoption of a carbohydrate- and fat-rich diet and a sedentary lifestyle. Mediterranean diet based on "modern" cereal and legume (often contaminated with GM) consumption no longer appears to be the "ideal diet" due to gluten added to modern flour, which is suspected to cause autoimmune diseases, and to the increasingly widespread consumption of milk and dairy products. Furthermore, attention should be paid to the need to consider the compatibility of foods with their own immune systems defined by the blood group.

Prenatal and childhood are critical periods in the development of overweight and obesity. The main risk factors are socioeconomic adversity, emotional turmoil and subtle junk food self-medication to alleviate uncomfortable emotional states. Over time this results in alterations in energy homeostasis, weight gain, and obesity [28]. The prevention plays a fundamental role in this delicate age range. Changing the advertising of food on children's TV, promoting nutritious foods and avoiding to advertisement of junk food would help to change eating behavior [29].

The problem of overeating in rich countries and the scarcity of food in poor countries should lead to a solution that makes available an equitable distribution of food in the world, rather than in creating new intensive production that damage the environment. The availability of healthy food for all people will prevent all forms of undernutrition, micronutrient deficiency, overweight and obesity and will reduce the risk of pathologies related to unhealthy diet. In addition, the attention to sustainability of food production will preserve biodiversity. Another cause of the unequal distribution of food around the world was generated by the current pandemic. In fact, the nutritional status of the population is likely to deteriorate due to the socio-economic impact of COVID-19, particularly in places where health, food and social protection programs are fragile or cannot be scaled up as needed [24].

The industrial food revolution changed our eating habits and our metabolism, introducing processed foods absent in ancient diet, thus contributing to the onset of some pathogenesis, called diseases of civilization. The business of food industry should be downsized in favor of morally or ethically fair choices for consumers and for the well-being of society [25].

Moreover, the intake of genetically modified (GM) food may alter the hematological, biochemical, and immunologic parameters causing some common toxic effects, such as hepatic, pancreatic, renal, or reproductive damages [87]. The possible side effects of GM food intake would recommend, according to the Precautionary Principle, the invitation to adopt a series of preventive measures before the damage occurs [88].

In order to improve diet habits influenced by a complexity of factors, active collaboration of a variety of actors is required throughout multiple sectors of the food system [63]. If it is true that consumers should be educated sufficiently to make wise food choices, it is also true that the food industry would have a moral obligation to provide healthy food to promote consumer health [63]. In this regard, additives, preservatives and flavor enhancers in food processing should be avoided (or at least limited to a scientifically required amount) in order to preserve consumer health. Existing rules on the use of additives should be subject to the parallel use of explanatory labels that are understandable to all consumers.

The main objective of the proposed health education program is to increase the self-awareness of one's body, to assist the individual in the recognition of the responsibility of safeguarding one's health and to prevent behavior harmful to health. Food education should provide for the removal/minimization of the factors responsible for incorrect eating behaviors through the attention of the mass media and food 
producers on consumer health rather than market logic. The person can be considered "healthy" to the extent that he is able to live freely and consciously [25].

The onset of new food processing technologies is changing and transforming food composition, and altering its physicochemical and immunogenic properties. Glucose, salt, emulsifiers, organic solvents, gluten, and nanoparticles are increasingly used by industry to improve organoleptic characteristics of food. However, food additives are suspected to altering intestinal permeability resulting in enhanced predisposition to autoimmune, allergic and malignant diseases [52]. Contrarily, the correct dietary regimen, by reducing obesity, in turn reduces inflammation, even during a viral infection such as the current COVID-19 infection that generate a mild or highly acute respiratory syndrome [40]. The intake of poorly selected food-products such as concentrated sugars and gluten supplementation in the modern flour products, and nutrients, as well as their excessive refining which remove important nutrients that contribute to impaired glucose metabolism can lead to diabetes. Low fiber intake, over-consumption of red meat (promoted mainly as a concomitant of intensive husbandry) cow's milk and dairy products and an imbalance of omega 3 and omega 6 fats all contribute to cancer risk. However, most of the research regarding nutrition and cancer is concerned with the onset and growth or reduction of tumor mass in relation to diet, and only recently prevention of cancer through healthy nutrition [89].

The strategy to be adopted to achieve universal well-being should be a synergistic collaboration between an ethical distribution of healthy food, governmental food education program, industrial ethics input, and timely, well-balanced oversight of food production.

\section{Conflict of interest}

None to report.

\section{Funding}

The study was carried out within the framework of the project OBE-S.O.S. (DER 2017-84455-R) "Hábitos de vida saludables y lucha contra la obesidad. Los retos del Derecho ante la salud alimentaria y la nutrición" financed by the Ministry of Economy of Spain, whose principal researchers are M.A. Torres López and L.J. Sánchez-Mesa Martínez.

\section{References}

[1] World Health Organization. The challenge of obesity in the WHO European Region and the strategies for response. 2007 [cited 2020, Aug 26]. Available from: https://wwweurowhoint/en/publications/abstracts/challenge-of-obesity-in-the-whoeuropean-region-and-the-strategies-for-response-the.

[2] Di Bella G. La scelta antitumore. Prevenzione, terapia farmacologica e stile di vita. Macro Edizioni; 2019.

[3] Wedell-Neergaard AS, Eriksen L, Grønbæk M, Pedersen BK, Krogh-Madsen R, Tolstrup J. Low fitness is associated with abdominal adiposity and low-grade inflammation independent of BMI. PLoS One. 2018;13(1):e0190645. doi:10.1371/journal.pone.0190645.

[4] Green WD, Beck MA. Obesity impairs the adaptive immune response to influenza virus. Ann Am Thorac Soc. 2017(Supplement_5):S406-9. doi:10.1513/AnnalsATS.201706-447AW.

[5] Silvestris E, de Pergola G, Rosania R, Loverro G. Obesity as disruptor of the female fertility. Reprod Biol Endocrinol. 2018;16(1):22. doi:10.1186/s12958-018-0336-z.

[6] Cooksey-Stowers K, Schwartz MB, Brownell KD. Food swamps predict obesity rates better than food deserts in the United States. Int J Environ Res Public Health. 2017;14(11):1366. doi:10.3390/ijerph14111366. 
[7] Goodarzi MO. Genetics of obesity: What genetic association studies have taught us about the biology of obesity and its complications. Lancet Diabetes Endocrinol. 2018;6(3):223-36. doi:10.1016/S2213-8587(17)30200-0.

[8] Botchlett R, Woo SL, Liu M, Pei Y, Guo X, Li H et al. Nutritional approaches for managing obesity-associated metabolic diseases. J Endocrinol. 2017;233(3):R145-71. doi:10.1530/JOE-16-0580.

[9] The Rome Declaration. Global Health Summit, 21 May, 2021 [cited 2021 Sept 16]. Available from: https://global-healthsummit.europa.eu/rome-declaration_en.

[10] Dehghan M, Akhtar-Danesh N, Merchant AT. Childhood obesity, prevalence and prevention. Nutr J. 2005;4:24. doi:10.1186/1475-2891-4-24.

[11] ten Have M, de Beaufort ID, Teixeira PJ, Mackenbach JP, van der Heide A. Ethics and prevention of overweight and obesity: An inventory. Obes Rev. 2011;12(9):669-79. doi:10.1111/j.1467-789X.2011.00880.x.

[12] ACOG Committee Opinion No. 763: Ethical considerations for the care of patients with obesity. Obstet Gynecol. 2019;133(1):e90-6. doi:10.1097/AOG.0000000000003015.

[13] Quek Y-H, Tam WWS, Zhang MWB, Ho RCM. Exploring the association between childhood and adolescent obesity and depression: A meta-analysis. Obes Rev. 2017;18:742-54.

[14] Lang JE, Bunnell HT, Hossain MJ, Wysocki T, Lima JJ, Finkel TH et al. Being overweight or obese and the development of asthma. Pediatrics. 2018;142(6):e20182119. doi:10.1542/peds.2018-2119.

[15] Di Cesare M, Sorić M, Bovet P, Miranda JJ, Bhutta Z, Stevens GA et al. The epidemiological burden of obesity in childhood: A worldwide epidemic requiring urgent action. BMC Med. 2019;17(1):212. doi:10.1186/s12916-019-1449-8.

[16] World Health Organization. WHO estimates of the global burden of foodborne diseases, 2015 [cited 2020 Aug 26]. Available from: https://wwwwhoint/foodsafety/publications/foodborne_disease/fergreport/en/.

[17] Vazquez CE, Cubbin C. Socioeconomic status and childhood obesity: A review of literature from the past decade to inform intervention research. Curr Obes Rep. 2020;9(4):562-70. doi:10.1007/s13679-020-00400-2.

[18] FAO and WHO. Sustainable healthy diets - Guiding principles 2019 Rome [cited 2021 Nov 11]. Available from: https://www.fao.org/3/ca6640en/ca6640en.pdf.

[19] Kelly T, Yang W, Chen CS, Reynolds K, He J. Global burden of obesity in 2005 and projections to 2030. Int J Obes (Lond). 2008;32(9):1431-7. doi:10.1038/ijo.2008.102.

[20] GBD 2015 Obesity Collaborators, Afshin A, Forouzanfar MH, Reitsma MB, Sur P, Estep K, Lee A et al. Health effects of overweight and obesity in 195 countries over 25 years. N Engl J Med. 2017;377(1):13-27. doi:10.1056/NEJMoa1614362.

[21] Chooi YC, Ding C, Magkos F. The epidemiology of obesity. Metabolism. 2019;92:6-10. doi:10.1016/j.metabol.2018. 09.005 .

[22] Ahrens W, Pigeot I, Pohlabeln H, De Henauw S, Lissner L, Molnár D et al. IDEFICS consortium. Prevalence of overweight and obesity in European children below the age of 10. Int J Obes (Lond). 2014;38(Suppl 2):S99107. doi:10.1038/ijo.2014.140.

[23] Stenmarck A, Jensen C, Quested T, Graham M. Estimated of European Food Waste Levels. Swedish Environmental Research Institute; 2016.

[24] Di Pietro M, Spagnolo A, Disturbi del comportamento alimentare. In: Bioetica Sgreccia E, Spagnolo A, Di Pietro M, editors. Milano: Vita e Pensiero; 1999.

[25] Caporale M, La sicurezza alimentare Nel diritto 2011 [cited 2020 Aug 25]. Available from: https://www.neldiritto.it/ sezioni/penale/8717/la-sicurezza-alimentare.html?sezione=penale\&key=MAria\%20Caporale.

[26] de Graaf C, Kok FJ. Slow food, fast food and the control of food intake. Nat Rev Endocrinol. 2010;6(5):290-3. doi:10.1038/nrendo.2010.41.

[27] Finelli C, Obesity and junk food: A strong correlation! EC Endocrinology and Metabolic Research ECO01. 2019;05-06.

[28] Hemmingsson E. Early childhood obesity risk factors: Socioeconomic adversity, family dysfunction, offspring distress, and junk food self-medication. Curr Obes Rep. 2018;7(2):204-9. doi:10.1007/s13679-018-0310-2.

[29] Dixon HG, Scully ML, Wakefield MA, White VM, Crawford DA. The effects of television advertisements for junk food versus nutritious food on children's food attitudes and preferences. Soc Sci Med. 2007;65(7):1311-23. doi:10.1016/j.socscimed.2007.05.011.

[30] Wen LM, Simpson JM, Rissel C, Baur LA. Maternal "junk food" diet during pregnancy as a predictor of high birthweight: Findings from the healthy beginnings trial. Birth. 2013;40(1):46-51. doi:10.1111/birt.12028.

[31] Kalra EK. Nutraceutical-Definition and introduction. AAPS PharmSci. 2003;5(3):E25. doi:10.1208/ps050325.

[32] Nasri H, Baradaran A, Shirzad H, Rafieian-Kopaei M. New concepts in nutraceuticals as alternative for pharmaceuticals. Int J Prev Med. 2014;5(12):1487-99.

[33] Smits RM, Mackenzie-Proctor R, Fleischer K, Showell MG. Antioxidants in fertility: Impact on male and female reproductive outcomes. Fertil Steril. 2018;110(4):578-80. doi:10.1016/j.fertnstert.2018.05.028. 
[34] Souter I, Chiu YH, Batsis M, Afeiche MC, Williams PL, Hauser R et al. EARTH Study Team. The association of protein intake (amount and type) with ovarian antral follicle counts among infertile women: Results from the EARTH prospective study cohort. BJOG. 2017;124(10):1547-55.doi:10.1111/1471-0528.14630.

[35] Bhattacharya K, Sengupta P, Dutta S, Karkada IR. Obesity, systemic inflammation and male infertility. Chem Biol Lett. 2020;7(2):92-8.

[36] Kiddy DS, Hamilton-Fairley D, Bush A, Short F, Anyaoku V, Reed MJ et al. Improvement in endocrine and ovarian function during dietary treatment of obese women with polycystic ovary syndrome. Clin Endocrinol (Oxf). 1992;36(1):105-11. doi:10.1111/j.1365-2265.1992.tb02909.x.

[37] Gaskins AJ, Sundaram R, Buck Louis GM, Chavarro JE. Seafood intake, sexual activity, and time to pregnancy. J Clin Endocrinol Metab. 2018;103(7):2680-8. doi:10.1210/jc.2018-00385.

[38] Chiu YH, Chavarro JE, Souter I. Diet and female fertility: Doctor, what should I eat? Fertil Steril. 2018;110(4):560-9. doi:10.1016/j.fertnstert.2018.05.027.

[39] Chiu YH, Williams PL, Gillman MW, Gaskins AJ, Mínguez-Alarcón L, Souter I et al. EARTH Study Team. Association between pesticide residue intake from consumption of fruits and vegetables and pregnancy outcomes among women undergoing infertility treatment with assisted reproductive technology. JAMA Intern Med. 2018;178(1):1726. doi:10.1001/jamainternmed.2017.5038.

[40] Jayarathne S, Koboziev I, Park OH, Oldewage-Theron W, Shen CL, Moustaid-Moussa N. Anti-inflammatory and antiobesity properties of food bioactive components: Effects on adipose tissue. Prev Nutr Food Sci. 2017;22(4):251-62 doi:10.3746/pnf.2017.22.4.251.

[41] Messina G, Polito R, Monda V, Cipolloni L, Di Nunno N, Di Mizio G et al. Functional role of dietary intervention to improve the outcome of COVID-19: A hypothesis of work. Int J Mol Sci. 2020;21(9):3104. doi:10.3390/ijms21093104.

[42] Francisco V, Pino J, Campos-Cabaleiro V, Ruiz-Fernández C, Mera A, Gonzalez-Gay MA et al. Obesity, fat mass and immune system: Role for leptin. Front Physiol. 2018;9:640. doi:10.3389/fphys.2018.00640.

[43] Castoldi A, Naffah de Souza C, Câmara NO, Moraes-Vieira PM. The macrophage switch in obesity development. Front Immunol. 2016;6:637. doi:10.3389/fimmu.2015.00637.

[44] Weihe P, Spielmann J, Kielstein H, Henning-Klusmann J, Weihrauch-Blüher S. Childhood obesity and cancer risk in adulthood. Curr Obes Rep. 2020;9(3):204-12. doi:10.1007/s13679-020-00387-w.

[45] Hicklin T. How Dietary Factors Influence Disease Risk. National Institute of Health; 2017 [cited 2020 Aug 25]. Available from: https://www.nih.gov/news-events/nih-research-matters/how-dietary-factors-influence-disease-risk.

[46] Acerra L. Il Mal di Latte Intolleranze, allergie e malattie da latte e latticini. Marco Editori; 2001.

[47] Di Fazio MR. Mangiare bene per sconfiggere il male. Mind Edizioni; 2016.

[48] Lu W, Chen H, Niu Y, Wu H, Xia D, Wu Y. Dairy products intake and cancer mortality risk: A meta-analysis of 11 population-based cohort studies. Nutr J. 2016;15(1):91. doi:10.1186/s12937-016-0210-9.

[49] Aslam H, Holloway-Kew KL, Mohebbi M, Jacka FN, Pasco JA. Association between dairy intake and fracture in an Australian-based cohort of women: A prospective study. BMJ Open. 2019;9(11):e031594. doi:10.1136/bmjopen-2019031594.

[50] Heine RG, Alrefaee F, Bachina P, De Leon JC, Geng L, Gong S et al. Lactose intolerance and gastrointestinal cow's milk allergy in infants and children - Common misconceptions revisited. World Allergy Organ J. 2017;10(1):41. doi:10.1186/s40413-017-0173-0.

[51] Davoodi H, Saeideh E, Mortazavian A. Effects of milk and milk products consumption on cancer: A review. Comprehensive Reviews in Food Science and Food Safety. 2013;12(3):249-65. doi:10.1111/1541-4337.12011.

[52] Chen L, Li M, Li H. Milk and yogurt intake and breast cancer risk: A meta-analysis. Medicine (Baltimore). 2019;98(12):e14900. doi:10.1097/MD.0000000000014900.

[53] Mancuso C, Barisani D. Food additives can act as triggering factors in celiac disease: Current knowledge based on a critical review of the literature. World J Clin Cases. 2019;7(8):917-27. doi:10.12998/wjcc.v7.i8.917.

[54] Lerner A, Ramesh A, Matthias T. Going gluten free in non-celiac autoimmune diseases: The missing ingredient. Expert Rev Clin Immunol. 2018;14(11):873-5. doi:10.1080/1744666X.2018.1524757.

[55] Fasano A. A Clinical Guide to Gluten-Related Disorders. 1 ed. Lippincott Williams \& Wilkins, A Wolters Kluwer Business; 2014.

[56] Casella G, Villanacci V, Di Bella C, Bassotti G, Bold J, Rostami K. Non celiac gluten sensitivity and diagnostic challenges. Gastroenterol Hepatol Bed Bench. 2018;11(3):197-202.

[57] Rotondi Aufiero V, Fasano A, Mazzarella G. Non-celiac gluten sensitivity: How its gut immune activation and potential dietary management differ from celiac disease. Mol Nutr Food Res. 2018;62(9):e1700854. doi:10.1002/mnfr.201700854.

[58] Losurdo G, Piscitelli D, Pezzuto F, Fortarezza F, Covelli C, Marra A et al. T helper lymphocyte and mast cell immunohistochemical pattern in nonceliac gluten sensitivity. Gastroenterol Res Pract. 2017;2017:5023680. doi:10.1155/2017/5023680. 
[59] Mozzi P, Mozzi M, Ziglio L. La dieta del dottor Mozzi Gruppi sanguigni e combinazioni alimentari. Coop Mogliazze; 2014.

[60] Calder PC, Kew S. The immune system: A target for functional foods? Br J Nutr. 2002;88(Suppl 2):S165-77. doi:10.1079/BJN2002682.

[61] Wu D, Lewis ED, Pae M, Meydani SN. Nutritional modulation of immune function: Analysis of evidence, mechanisms, and clinical relevance. Front Immunol. 2019;9:3160. doi:10.3389/fimmu.2018.03160.

[62] D’Adamo PJ, Whitney C. Eat Right 4 Your Type: The Individualized Blood Type Diet Solution. Berkley Books; 2016.

[63] GBD 2017 Diet Collaborators. Health effects of dietary risks in 195 countries, 1990-2017: A systematic analysis for the Global Burden of Disease Study 2017. Lancet. 2019;393(10184):1958-72. doi:10.1016/S0140-6736(19)30041-8. Epub 2019 Apr 4. Erratum in: Lancet. 2021;397(10293):2466.

[64] Carr AC, Maggini S. Vitamin C and immune function. Nutrients. 2017;9(11):1211. doi:10.3390/nu9111211.

[65] Segerstrom SC, Miller GE. Psychological stress and the human immune system: A meta-analytic study of 30 years of inquiry. Psychol Bull. 2004;130(4):601-30. doi:10.1037/0033-2909.130.4.601.

[66] Maywald M, Wessels I, Rink L. Zinc signals and immunity. Int J Mol Sci. 2017;18(10):2222. doi:10.3390/ijms18102222.

[67] Whelan J, Gowdy KM, Shaikh SR. N-3 polyunsaturated fatty acids modulate B cell activity in pre-clinical models: Implications for the immune response to infections. Eur J Pharmacol. 2016;785:10-7. doi:10.1016/j.ejphar.2015.03.100.

[68] FAO and WHO. Evaluation of Health and Nutritional Properties of Probiotics in Food Including Powerder Milk and Live Lactic Acid Bacteria. Food and Agriculture Organization of the United Nations and World Health Organization. Expert Consultation Report. 2001. p 1-34 [cited 2020 Aug 25]. Available from: http://wwwfaoorg/3/a-a0512epdf.

[69] Visher E, Whitefield SE, McCrone JT, Fitzsimmons W, Lauring AS. The mutational robustness of influenza a virus. PLoS Pathog. 2016;12(8):e1005856. doi:10.1371/journal.ppat.1005856.

[70] Calder PC, Carr AC, Gombart AF, Eggersdorfer M. Optimal nutritional status for a well-functioning immune system is an important factor to protect against viral infections. Nutrients. 2020;12(4):1181. doi:10.3390/nu12041181.

[71] Lopez-Legarrea P, Fuller NR, Zulet MA, Martinez JA, Caterson ID. The influence of Mediterranean, carbohydrate and high protein diets on gut microbiota composition in the treatment of obesity and associated inflammatory state. Asia Pac J Clin Nutr. 2014;23(3):360-8. doi:10.6133/apjen.2014.23.3.16.

[72] Natarajan N, Hori D, Flavahan S, Steppan J, Flavahan NA, Berkowitz DE et al. Microbial short chain fatty acid metabolites lower blood pressure via endothelial G protein-coupled receptor 41. Physiol Genom. 2016;48(11):826-34. doi:10.1152/physiolgenomics.00089.2016.

[73] Al-Assal K, Martinez AC, Torrinhas RS, Cardinelli C, Waitzberg D. Gut microbiota and obesity. Clin Nutr Exp. 2018;20:60-4.

[74] Barazzoni R, Bischoff SC, Busetto L, Cederholm T, Chourdakis M, Cuerda C et al. endorsed by the ESPEN Council. Nutritional management of individuals with obesity and COVID-19: ESPEN expert statements and practical guidance. Clin Nutr. 2021;S0261-5614(21)00248-X. doi:10.1016/j.clnu.2021.05.006.

[75] Simonnet A, Chetboun M, Poissy J, Raverdy V, Noulette J, Duhamel A et al. LICORN and the Lille COVID-19 and Obesity Study Group. High prevalence of obesity in severe acute respiratory syndrome coronavirus-2 (SARS-CoV-2) requiring invasive mechanical ventilation. Obesity (Silver Spring). 2020;28(7):1195-9. doi:10.1002/oby.22831. Epub 2020 Jun 10. Erratum in: Obesity (Silver Spring). 2020;28(10):1994.

[76] Morgan OW, Bramley A, Fowlkes A, Freedman DS, Taylor TH, Gargiullo P et al. Morbid obesity as a risk factor for hospitalization and death due to 2009 pandemic influenza A(H1N1) disease. PLoS One. 2010;5(3):e9694. doi:10.1371/journal.pone.0009694.

[77] Louie JK, Acosta M, Samuel MC, Schechter R, Vugia DJ, Harriman K et al. California Pandemic (H1N1) Working Group. A novel risk factor for a novel virus: obesity and 2009 pandemic influenza A (H1N1). Clin Infect Dis. 2011;52(3):30112. doi:10.1093/cid/ciq152.

[78] Yang J, Hu J, Zhu C. Obesity aggravates COVID-19: A systematic review and meta-analysis. J Med Virol. 2020;30. doi:10.1002/jmv.26237.

[79] Sattar N, McInnes IB, McMurray JJV. Obesity is a risk factor for severe COVID-19 infection: Multiple potential mechanisms. Circulation. 2020;142(1):4-6. doi:10.1161/CIRCULATIONAHA.120.047659.

[80] Cierco Seira C, Administración Pública y Salud colectiva El marco jurídico de la protección frente a las epidemias y otros riesgos sanitarios. Comares. 2006.

[81] Bombillar Sáenz FM, Salus publica suprema lex esto: la protección frente a las epidemias y otros riesgos sanitarios desde el Derecho administrativo espa nol a propósito del Covid-19. Law against pandemic. 2020 [cited 2020 Aug 25]. Available from: https://lawagainstpandemicujedupl/2020/04/10/salus-publica-suprema-lex-esto/.

[82] Thaler R, Sunstein CR. Nudge Improving Decisions About Health, Wealth, and Happiness. New Haven \& London: Yale University Press; 2008. 
[83] Sartori G. Homo videns La sociedad teledirigida. Madrid: Taurus; 1997.

[84] Rozados Oliva MJ, Derecho Administrativo de la Publicidad. Tirant lo Blanch. 2009.

[85] Castro-Jiménez RA, Fonseca Del Pozo FJ, Jiménez Moral G, Fruet-Cardozo JV. Analysis of health habits, vices and interpersonal relationships of Spanish adolescents, using SEM statistical model. Heliyon. 2020;6(8):e04699. doi:10.1016/j.heliyon.2020.e04699.

[86] Fanzo J. Ethical issues for human nutrition in the context of global food security and sustainable development. Global Food Security. 2015;7:15-23.

[87] Dona A, Arvanitoyannis IS. Health risks of genetically modified foods. Crit Rev Food Sci Nutr. 2009;49(2):164-75. doi:10.1080/10408390701855993.

[88] National Bioethics Committee. The precautionary principle: Bioethical, philosophical, legal aspects. 18th of June. 2004 [cited 2020 Aug 26]. Available from: http://bioeticagovernoit/en/opinions/opinions-responses/precautionary-principlebioethical-philosophical-and-legal-aspects/.

[89] Kushi LH, Byers T, Doyle C, Bandera EV, McCullough M, McTiernan A et al. American Cancer Society 2006 Nutrition and Physical Activity Guidelines Advisory Committee. American Cancer Society Guidelines on Nutrition and Physical Activity for cancer prevention: Reducing the risk of cancer with healthy food choices and physical activity. CA Cancer J Clin. 2006;56(5):254-81; quiz 313-4. doi:10.3322/canjclin.56.5.254. Erratum in: CA Cancer J Clin. 2007;57(1):66. 